\title{
Swallowing disorders after ischemic stroke
}

\author{
Gabriela Camargo Remesso', Márcia Maiumi Fukujima², \\ Ana Lúcia de Magalhães Leal Chiappetta', Adriana Leico Oda', \\ Alexandre Santos Aguiar, Acary de Souza Bulle Oliveira², \\ Gilmar Fernandes do Prado 2
}

\begin{abstract}
Objective: To investigate occurrences of swallowing disorders after ischemic stroke. Method: This was a retrospective study on 596 medical files. The inclusion criterion was that the patients needed to have been hospitalized with a diagnosis of ischemic stroke; the exclusion criteria were the presence of associated cardiac problems and hospital stay already more than 14 days. Results: $50.5 \%$ were men and $49.5 \%$ women; mean age 65.3 years $(S D= \pm 11.7)$ ( $p \leq 0.001)$. Among the risk factors, $79.4 \%$ had hypertension, $36.7 \%$ had diabetes ( $p \leq 0.001$ ) and $42.7 \%$ were smokers. $13.3 \%$ of the patients died. Swallowing disorders occurred in $19.6 \%$, among whom $91.5 \%$ had mild difficulty and $8.5 \%$ had severe difficulty. $87.1 \%$ had spontaneous recovery after a mean of 2.4 months. A lesion in the brainstem region occurred in 6.8\% ( $p \leq 0.001)$. Conclusion: Swallowing disorders occurred in almost $20 \%$ of the population and most of the difficulty in swallowing found was mild. The predictors for swallowing disorders were older age, diabetes mellitus and lesions in the brainstem region.
\end{abstract}

Key words: swallowing disorders, dysphagia, stroke, epidemiology.

\section{Alteração da deglutição após acidente cerebrovascular isquêmico}

\section{RESUMO}

Objetivo: Verificar alteração da deglutição após acidente cerebrovascular isquêmico (AVCI). Método: Estudo retrospectivo de 596 prontuários. Critérios de inclusão: pacientes hospitalizados com diagnóstico de AVCl. Critérios de exclusão: pacientes com problemas cardíacos associados e com mais de 14 dias de internação. Resultados: 50,5\% homens e $49,5 \%$ mulheres, idade média 65,3 anos ( $D P= \pm 11,7)(p \leq 0,001)$. Entre os fatores de risco, $79,4 \%$ hipertensão arterial, 36,7\% diabetes ( $p \leq 0,001)$, 42,7\% tabagismo. Óbito ocorreu em $13,3 \%$ dos pacientes. Alteração de deglutição ocorreu em 19,6\%, sendo 91,5\% com dificuldade leve e 8,5\% com dificuldade grave; $87,1 \%$ tiveram recuperação espontânea com tempo médio de 2,4 meses. A lesão em região de tronco encefálico ocorreu em $6,8 \%$ ( $p \leq 0,001)$. Conclusão: A alteração da deglutição ocorreu em quase 20\% da população e a dificuldade de deglutição mais encontrada foi a leve. Os fatores preditores para alteração de deglutição foram aumento da idade, diabetes mellitus e lesão em região de tronco encefálico.

Palavras-Chave: alteração da deglutição, disfagia, acidente cerebrovascular, epidemiologia.

\section{Correspondence}

Gabriela Camargo Remesso Av. Leôncio de Magalhães 1004 / cj. 82 02040-001 São Paulo SP - Brasil

E-mail: gabrielaremesso@uol.com.br

Received 2 September 2010

Received in final for 21 June 2011 Accepted 28 June 2011
Cerebrovascular disease is the leading cause of death in Brazil and occurs most frequently in individuals who are at least 60 years of age. It is the most disabling disease and has great social, economic and psychological impact ${ }^{1,2}$.

Swallowing disorders after a stroke are common occurrences, with high inci- 
dence ranging from $18 \%$ to $81 \%$ in the acute phase and with prevalence of $12 \%$ among such patients $s^{3-5}$. Studies making objective assessments through swallowing examinations have shown that the prevalence of aspiration may reach $55 \%$, and that around $45 \%$ of the cases result in death ${ }^{6,7}$. Among the most frequent complications of dysphagia are increased mortality, pulmonary risks such as aspiration pneumonia, dehydration, malnutrition and long-term hospitalization ${ }^{3,4,8,9}$. Surveys have shown that the predictors of dysphagia in clinical assessments include older age, greater severity of stroke, wet vocal quality, abnormal palatal reflex, weak or absent cough, abnormal voluntary cough, coughing with swallowing and injury sustained in controlling secretions ${ }^{9,10}$.

Ischemic stroke occurs more frequently than hemorrhagic stroke, although the hemorrhagic type is more likely to cause greater severity of dysphagia ${ }^{11,12}$. Regarding the topography of the lesion, it is important to show that cortical lesions may give rise to difficulty in controlling the voluntary movements of chewing, thus impairing transportation of the food bolus during the oral and pharyngeal phase of swallowing, and increasing the chances of tracheal aspiration. Brainstem lesions are less frequent, but result in severe impairment of swallowing because of the location of most of the nuclei of the cranial nerves ${ }^{3,11,12}$.

Studies have suggested that the recovery from dysphagia occurs soon after the stroke, taking between two and four weeks. It has also been shown that, six months after the stroke, deglutition abnormalities are present in $50 \%$ of such patients ${ }^{9,13,14}$.

The objective of this study was to investigate occurrences of swallowing disorders after an ischemic stroke.

\section{METHOD}

This study was based on retrospective analyses on 596 medical files of patients who had an ischemic stroke between November 1998 and December 2006. Of these, 299 (50.1\%) were women and 297 (49.9\%) were men. They were treated at the Federal University of São Paulo (UNIFESP/EPM), and were participants in a clinical trial on transesophageal echocardiography and doses of aspirin that was partly published in February $2005^{2}$.

The inclusion criterion was that the patients needed to have been hospitalized with a diagnosis of ischemic stroke confirmed by clinical examination and computed tomography or magnetic resonance imaging. The exclusion criteria were the presence of associated cardiac problems and hospital stay already more than 14 days.

The study consisted of collecting demographic and clinical data relating to patient identification (gender, age and education), risk factors (hypertension, diabetes mellitus, cerebrovascular disease, peripheral vascular disease, body mass index, smoking and alcoholism) and swallowing disorders (mild or severe, as classified by the medical staff). The topography of the lesion was classified from CT or MRI diagnostic imaging examinations as right hemisphere, left hemisphere, multiple lesions (in both hemispheres), brainstem or cerebellum. Occurrences of death were also analyzed.

The evaluation of swallowing was performed by the medical team, and it began with direct questions about patients' food intake and their complaints about swallowing difficulties. These swallowing complaints were classified as mild when oral control was uncoordinated and ejection of the bolus was slow, with no choking or coughing during or after swallowing (patient complaints about chewing). Severe disorders occurred when the patient presented great difficulty in swallowing food, with constant presence of coughing and choking during feeding. The swallowing disorders were classified based on criteria established in a previous study: "Neurogenic Oropharyngeal Dysphagia After Stroke"11.

Consent statements were previously obtained in relation to the clinical trial ${ }^{2}$. Because the present study was a retrospective analysis of medical records, no free and informed consent statement was requested specifically for this analysis.

This research was reviewed and approved by the Research Ethics Committee of the Federal University of São Paulo / Escola Paulista de Medicina, under paragraph 197/08. It was deemed not to involve risk and not to require consent. The study was presented to obtain the title of Neurological Rehabilitation Specialist, in the Department of Neurology, Federal University of São Paulo / Escola Paulista de Medicina.

In the univariate analysis, the chi-square test was applied to dichotomous variables and the Student t test to numerical variables. In multivariate analysis to detect predictors for swallowing disorders and spontaneous recovery from swallowing disorders, the variables selected were those in which the significance tests in the univariate analysis resulted in $p \leq 0.15$. To determine whether differences existed, we adopted the value of $p<0.05$. The analysis had two phases. The first compared patients with swallowing disorder and patients without swallowing disorder. In the second, only the subgroup with swallowing disorders was analyzed, regardless of whether spontaneous recovery occurred or not.

\section{RESULTS}

The sample comprised 299 women (50.1\%) and 297 men $(49.9 \%)$, with an average age of 62 years $(S D= \pm 12.2)$, ranging from 26 to 92 years $(\mathrm{p} \leq 0.001)$. Swallowing disorders were most prevalent among the patients aged 60 
Table 1. Sociodemographic data.

\begin{tabular}{lccc}
\hline & With swallowing disorders & Without swallowing disorders & $\mathrm{p}$ \\
\hline $\mathrm{n}(\%)$ & $117(19.7)$ & $479(80.33)$ & \\
Gender $\mathrm{n}(\%)$ & & $\mathrm{NS}$ & \\
$\quad$ Male & $59(50.5)$ & $238(49.6)$ & \\
$\quad$ Female & $58(49.5)$ & $241(50.3)$ & $<0.001$ \\
Age $($ mean \pm SD) & $65.3( \pm 11.7)$ & $\mathrm{NS}$ & \\
Schooling $\mathrm{n}(\%)$ & & $316(65.9)$ & \\
0-4 years & $77(65.8)$ & $85(17.7)$ & \\
5-8 years & $20(17.1)$ & $60(12.5)$ & \\
$9-12$ years & $14(11.9)$ & $16(13.3)$ & \\
$>12$ years & $6(5.1)$ &
\end{tabular}

Descriptive statistical analysis and t test. NS: not significant; SD: standard deviation.

Table 2. Analysis on risk factors and deaths in the group presenting swallowing disorders.

\begin{tabular}{|c|c|c|c|}
\hline & $\begin{array}{l}\text { With swallowing } \\
\text { disorders }(n=117)\end{array}$ & $\begin{array}{l}\text { Without swallowing } \\
\text { disorders }(n=479)\end{array}$ & $\mathrm{p}$ \\
\hline Hypertension (n\%) & $93(79.4)$ & $389(81.2)$ & NS \\
\hline Diabetes mellitus (n\%) & $43(36.7)$ & $118(24.6)$ & 0.01 \\
\hline Cerebrovascular disease (n\%) & $35(29.9)$ & $105(21.9)$ & NS \\
\hline Peripheral vascular disease (n\%) & $3(2.5)$ & $15(3.1)$ & NS \\
\hline Body mass index (mean $\pm S D$ ) & $5.8( \pm 4.1)$ & $26.1( \pm 1.4)$ & NS \\
\hline Smoking (n\%) & $50(42.7)$ & $177(36.9)$ & NS \\
\hline Alcoholism (n\%) & $22(18.8)$ & $91(18.9)$ & NS \\
\hline Death $(n \%)$ & $18(13.3)$ & $36(7.5)$ & NS \\
\hline
\end{tabular}

Descriptive statistical analysis and t test. NS: not significant; SD: standard deviation.

Table 3. Topography of lesion in the group presenting swallowing disorders.

\begin{tabular}{lccc} 
& $\begin{array}{c}\text { With swallowing } \\
\text { disorders }(\mathrm{n}=117)\end{array}$ & $\begin{array}{c}\text { Without swallowing } \\
\text { disorders }(\mathbf{n}=479)\end{array}$ & $\mathrm{p}$ \\
\hline Right hemisphere $(\mathrm{n} \%)$ & $46(39.3)$ & $185(38.6)$ & NS \\
Left hemisphere $(\mathrm{n} \%)$ & $47(40.1)$ & $218(45.5)$ & NS \\
Multiple $(\mathrm{n} \%)$ & $10(8.5)$ & $42(8.6)$ & NS \\
Brainstem (n\%) & $8(6.8)$ & $13(2.6)$ & 0.022 \\
Cerebellum (n\%) & $4(3.4)$ & $23(4.8)$ & NS \\
\hline
\end{tabular}

Descriptive statistical analysis and t test. NS: not significant.

years and over. The educational data showed that the patients had had an average of 4.6 years of school education $(\mathrm{SD}= \pm 4)$, with a range from illiterate to 27 years of education (Table 1).

Regarding the risk factors analyzed in the group of patients with swallowing disorders, $36.7 \%$ of these patients presented diabetes mellitus, which was statistically significant $(\mathrm{p}=0.010), 29.9 \%$ presented cerebrovascular disease, $7 \%$ were smokers and $13.3 \%$ died (Table 2).

Regarding the topography of the neurological injury, $6.8 \%$ of the patients had brainstem lesions and this was significantly greater $(\mathrm{p} \leq 0.001)$ for the group with swallowing disorders (Table 3 ).
Table 4. Predictors for swallowing disorders.

\begin{tabular}{lccc}
\hline & $\begin{array}{c}\text { Relative } \\
\text { risk }\end{array}$ & $\begin{array}{c}\text { Lower limit } \\
\text { of } 95 \% \mathrm{Cl}\end{array}$ & $\begin{array}{c}\text { Upper limit } \\
\text { of } 95 \% \mathrm{Cl}\end{array}$ \\
\hline Age & 1.03 & 1.01 & 1.05 \\
Diabetes mellitus & 1.70 & 1.25 & 2.15 \\
Brainstem & 2.59 & 1.61 & 3.57 \\
\hline
\end{tabular}

Cl: confidence interval.

The search for predictors for swallowing disorders, using logistic regression, revealed that age, stroke in the brainstem region and diabetes mellitus acted as predictors for swallowing disorders. The relative risks and their confidence intervals are shown in Table 4. 
Swallowing disorders occurred in 117 patients (19.6\%), with mild disorders in 107 (91.5\%) and severe disorders in 10 (8.5\%). Spontaneous recovery occurred in 102 patients (87.3\%). The time taken for spontaneous recovery to occur ranged from 1 to 16 months with an average of 2.4 months $(\mathrm{SD}= \pm 2.7)$.

\section{DISCUSSION}

Studies on the incidence of dysphagia after stroke are common because stroke is a neurological disorder that affects many people around the world, particularly those over 60 years of age. The risk factors of hypertension, diabetes mellitus and smoking, associated with stress and sedentary lifestyles, are the biggest cause of stroke. In most cases, stroke can lead to motor sequelae, functional disability and language deficit. Dysphagia can also occur, and the early symptoms depend on the location of the neurological injury. Studies have varied with regard to the time at which swallowing assessments are made (which may be from the acute to the chronic phase), the protocols used, the professionals who perform the evaluation and the use of specific tests for diagnosing swallowing difficulties.

In relation to gender, the sample was homogeneous and did not show any differences. This was also found in other studies: in one with 1,581 patients, $51.1 \%$ were men; while in another with 400 patients, $52.2 \%$ were men. In a study with a smaller number (128 patients), $64 \%$ were male ${ }^{14-16}$.

The age of the patients who presented swallowing disorders averaged 65 years, which was in agreement with other studies, in which the greater number of swallowing disorders was found at the ages of 65 to 74 years $^{4,14,17}$. Another study found that greater age ( $\geq 70$ years) was a predictive factor for swallowing disorders ${ }^{10}$. We believe that the greater the age is, the greater the chances are that the aging body becomes phonoarticulatory (lips, tongue and cheeks), which would undermine the functions of the stomatognathic system (chewing, swallowing, respiration, voice and speech) and subsequently cause swallowing disorders, especially after stroke e,10,14,17 $^{\text {. }}$

The number of patients with an education level of between 0 and 4 years $(66.1 \%)$ was higher than the numbers in other educational levels. This was concordant with another study, in which $71.4 \%$ of the patient sample had a similar educational level, typical of a developing country like Brazil ${ }^{16}$.

Regarding risk factors, diabetes mellitus was a predictor for swallowing disorders. Other studies in the literature found that dysphagia, urinary incontinence and diabetes mellitus were independent predictors for increased levels of infections after stroke. Most of the patients had hypertension, followed in frequency by diabetes mel- litus, and smoking was in third place. These findings were similar to other studies on risk factors for stroke ${ }^{15,16}$.

The topography of lesions in patients with swallowing disorders was similar for the right and left hemispheres (39.3\% and 40.1\%). On the other hand, the small number of patients with lesions in both hemispheres (8.5\%) was discordant with other studies, which showed that $51.8 \%$ of the patients with swallowing disorders had lesions in both hemispheres ${ }^{18}$, and that $63.6 \%$ had the largest lesion in the right hemisphere ${ }^{19}$.

Presence of brainstem lesions was predictive for swallowing disorders. Lesions in this region could affect the sensitivity of the oral cavity, tongue and cheeks, and could trigger swallowing disorders and laryngeal elevation ${ }^{20-23}$.

Swallowing disorders were found in almost 20\% of the patients, according to a study on a large number of patients $(\mathrm{n}=1581)$. The incidence of dysphagia in that study $(19.9 \%)$ was very similar to our finding ${ }^{15}$. However, the incidence of dysphagia may vary according to the time elapsed after the stroke, the severity of the stroke and the method of assessing the swallowing complaint and locating the lesion, i.e. by clinical means or by using instruments like videofluoroscopy or endoscopy. Thus, studies have shown a range from 18 to $81 \%^{3-5,10,14,22}$.

Slight difficulty in swallowing was more frequently found (91.5\%), and this was similar to a study conducted in Brazil, in which $70 \%$ of the patients showed a mild disorder $^{4}$. The explanation for our results is that our sample excluded severe cases and patients who had already been in hospital for more than 14 days. Such cases would be more likely to show abnormalities of swallowing. Our patients were seen at the clinic within 30 days after hospital discharge, which was in accordance with the literature, which shows that swallowing disorders are greatest in severe stroke cases and in the acute phase of stroke ${ }^{13}$.

Spontaneous recovery occurred in almost $90 \%$ of the sample, with an average time elapsed of two months. Only $12 \%$ did not recover and continued to have complaints relating to swallowing. These results were in agreement with other studies that showed that recovery of swallowing occurred over the first few weeks after the event, and that swallowing disorders only remained in a small number of patients ${ }^{9,10,13,14}$. A study using functional magnetic resonance imaging among dysphagia patients showed that among patients who had recovered within a short period of time, cortical maps in the hemisphere not affected by stroke explained this as reorganization in the cortex ${ }^{5}$.

In our sample, patients who showed abnormalities of swallowing had higher mortality rates. This finding was concordant with the literature, which shows that dysphagia may be associated with aspiration of saliva or food and can cause lung infections, dehydration and mal- 
nutrition. It is thus an independent sign of worse outcomes and increased mortality after stroke ${ }^{12,13}$. Recognizing this is extremely important for the performance of the speech therapy team in relation to stroke patients, in order to prevent and reduce hospital admissions and readmissions due to aspiration pneumonia, thereby aiming to stabilize the nutritional characteristics and improve the patients' quality of life $\mathrm{e}^{24,25}$.

In conclusion, sallowing disorders after a stroke occurred in almost $20 \%$ of the population and the difficulty in swallowing was most frequently mild.

\section{REFERENCES}

1. Lotufo AP, Bensenor IM. Stroke mortality in São Paulo (1997-2003). Arq Neuropsiquiatr 2004;62:1008-1011.

2. Fukujima MM, Tatiani SB, Aguiar AS, et al. Transesophageal echocardiography discloses unexpected cardiac sources of embolus in stroke patients aged more than 45 years. Arq Neuropsiquiatr 2005;63:941-945.

3. Martino R, Foley N, Bhogal S, Diamant N, Speechley M, Teasell R. Dysphagia after stroke, incidence, diagnosis, and pulmonary complications. Stroke 2005:36:2756.

4. Schelp AO, Cola PC, Gatto AR, Silva RG, Carvalho LR. Incidência de disfagia orofaríngea após acidente vascular encefálico em hospital público de referência. Arq Neuropsiquiatr 2004;62:503-506.

5. Singh S, Hamdy S. Dysphagia in stroke patients. Postgrad Med J 2006:82:383-391.

6. Perman AL. Dysphagia: populations at risk and methods diagnosis. Nut Clin Prat (Suppl) 1999;14:S2-S9.

7. Cook IJ, Kahrilas PJAGA. Techinical review on management of oropharyngeal dysphagia. Gastroenterology 1999;116:456-579.

8. Carnaby G, Hankey GJ, Pizzi J. Behavioural intervention for dysphagia in acute stroke: a randomized controlled trial. Lancet Neurol 2006;5:31-37.

9. Ramsey DJC, Smithard DG. Early assessments of dysphagia and aspiration and aspiration risk in acute stroke patients. Stroke 2003;34:1252.

10. Mann G, Hankey GJ. Initial clinical and demographic predictores of swallowing impairment following acute stroke. Dysphagia 2001;16:208-215.
11. Silva RG. Disfagia neurogênica em adultos pós-acidente vascular encefálico: identificação e classificação. Dissertação de Mestrado, Universidade Federal de São Paulo, São Paulo 1997.

12. Paciaroni M, Mazzotta G, Corea F, et al. Dysphagia following stroke. Eur Neurol 2004; 51:162-167.

13. Smithard DG, O'Neill PA, Park C, Morris J, Wyatt R, England R. Complications and outcomes after acute stroke. Stroke 1996:27:1200-1204.

14. Mann G, Hankey GJ, Cameron D. Swallowing function after stroke, prognosis and prognostic factors at 6 months. Stroke 1999;30:744-748.

15. Roquer J, Campello AR, Gomis M. Sex differences in first-ever acute stroke. Stroke 2003;34:1581-1585.

16. Shafaee MAA, Ganguly SS, Asmi ARA. Percepcion of stroke and knowledge of potential risk factores among Omani patients at increased risk for stroke. BMC Neurology 2006;6:38.

17. Ros L, García M, Prat J, et al. Predictors of nosocomial infection in acute stroke. Relation with morbimortality and outcome. Med Clin (Barc) 2007;128:441-447.

18. Parker C, Power M, Hamdy S, Bowen A. Awareness of dysphagia by patients following stroke predicts swallowing performance. Dysphagia 2004;19:28-35.

19. Daniels SK, Brailey K, Foundas AL. Lingual discordination and dysphagia follwing acute stroke:analyses os lesion localization. Dysphagia 1999; 14:85-92.

20. Veis SL, Logemann JA. Swallowing disorders in persons with cerebrovascular accident. Arch Phys Med Rehabil 1985;66:372-375.

21. Martino R, Terrault N, Ezerzer F, Mikulis D, Diamant NE. Dysphagia in a patient with medullary syndrome: insight into the central control of swallowing. Gastroenterology 2001;121:420-426.

22. Barros AFF, Fabio SRC, Furkin AM. Correlação entre os achados clínicos da deglutição e os achados da tomografia computadorizada de crânio em pacientes com acidente vascular cerebral isquêmico na fase aguda da doença. Arq Neuropsiquiatr 2006;64:1009-1014.

23. Leder SB, Espinosa JF. Aspiration risk after acute stroke: comparison of clinical examination and fibroscopic evaluation of swallowing. Dysphagia 2002;17:214-218.

24. Padovani AR, Moraes AP, Mangili LD, Andrade CRF. Protocolo fonoaudiológico de avaliação do risco para disfagia (PARD). Rev Soc Bras Fonoaudiol 2007;12:199-205.

25. Silva RG. A eficácia da reabilitação em disfagia orofaríngea. Pró-Fono Revista de Atualização Científica 2007;19:123-130. 